\title{
The Need for Subdividing the Enhanced Recovery Program and Evaluation Criteria After Colorectal Surgery
}

\author{
In Ja Park \\ Department of Colon and Rectal Surgery, Asan Medical Center, University of Ulsan College of Medicine, Seoul, Korea
}

\section{See Article on Page 86-92}

The enhanced postoperative recovery (EPR) program is designed to reduce organ dysfunction after surgery, which improves morbidity and speeds recovery by attenuating surgical stress or pain. The main focus of the program is to reduce the use of nasogastric tubes, drains, urinary catheters, and preoperative bowel preparations as compared to conventional recovery procedures and to initiate oral feeding and activities soon after surgery. The application of the EPR program to clinical practice has become easier with improvements in methods used for anesthesia and pain control and with the introduction of minimally invasive surgery.

In the 1990s, EPR was successfully employed for the first time after colon surgery [1]. Results from a number of randomized controlled trials, systematic reviews, and meta-analyses support the application of EPR after colon surgery [2-7]. According to these analyses, the use of EPR after colon surgery reduces hospital stay and medical cost. It decreases postoperative complications, as well. Initially, the readmission rate was known to be higher for patients who experienced EPR than it was for patients who experienced conventional recovery, but recently, reports have indicated no significant differences in those readmission rates. Therefore, the current evidence indicates that EPR can be safely applied after colon surgery.

Shetiwy et al. [8] faithfully confirmed the benefits of EPR. The authors found that the introduction of EPR shortened hospital stay and made postoperative recovery faster because the nasogastric tubes and drains were removed earlier and enteral feeding

Correspondence to: In Ja Park, M.D.

Department of Colon and Rectal Surgery, Asan Medical Center, University of Ulsan College of Medicine, 88 Olympic-ro 43-gil, Songpa-gu, Seoul 05505, Korea

Tel: +82-2-3010-3937, Fax: +82-2-474-9027

E-mail: ipark@amc.seoul.kr

(c) 2017 The Korean Society of Coloproctology

This is an open-access article distributed under the terms of the Creative Commons Attribution NonCommercial License (http://creativecommons.org/licenses/by-nc/4.0) which permits unrestricted noncommercial use, distribution, and reproduction in any medium, provided the original work is properly cited. was started more quickly. Postoperative complications were also reduced because of EPR without affecting the readmission rate, confirming its advantages. This comparison, however, might be a little unfair because EPR specifies that the nasogastric tubes and drains are to be removed and enteral feeding is to be started immediately after surgery. Moreover, the occurrence of anastomotic leakage, a complication that is considered to be unrelated to EPR, was $20 \%$ in the conventional group but was only $2.9 \%$ in the EPR group. This significant difference may have contributed to the longer hospital stay for patients in the conventional group. The distributions of lesion locations in the patients were reported not to be statistically different between the groups. However, $17 \mathrm{pa}-$ tients (48.6\%) in the conventional group had lesions located in the rectosigmoid and rectum, compared to 11 patients (31.4\%) in the EPR group. Thus, whether or not a difference in lesion location is linked to a difference in the rate of complications needs to be investigated further.

So far, the validity of using EPR for patients with lesions in different locations has not been established. Even in randomized controlled trials, the patients presented with lesions spread throughout the entire body, although their locations were distributed evenly. Clearly, rectal lesions are closely associated with serious complications such as leakage and ostomy formation. Therefore, rectal lesions should be differentiated from colon lesions in the composition of the EPR program. Before developing such programs, the completeness of the EPR program needs to be evaluated for each lesion location, and the reasons some patients with specific lesions are not amenable to EPR needs to be addressed.

Furthermore, most criteria used to evaluate the merits of EPR have been objective factors. Based on studies so far, EPR clearly has an advantage with regard to these objective factors. However, few studies have evaluated the alleviation of patients' stress, which was the original intent of EPR. Therefore, now is the appropriate time to establish evaluation criteria in terms of quality of life to look back on whether the aims of EPR development have been met. Also, the increasing burden on the referral center arising from early discharge needs to be evaluated, and the resulting alterations in medical cost and system operations need to be considered. 


\section{CONFLICT OF INTEREST}

No potential conflict of interest relevant to this article was reported.

\section{REFERENCES}

1. Kehlet H, Dahl JB. Anaesthesia, surgery, and challenges in postoperative recovery. Lancet 2003;362:1921-8.

2. Wind J, Polle SW, Fung Kon Jin PH, Dejong CH, von Meyenfeldt MF, Ubbink DT, et al. Systematic review of enhanced recovery programmes in colonic surgery. Br J Surg 2006;93:800-9.

3. Khoo CK, Vickery CJ, Forsyth N, Vinall NS, Eyre-Brook IA. A prospective randomized controlled trial of multimodal perioperative management protocol in patients undergoing elective colorectal resection for cancer. Ann Surg 2007;245:867-72.

4. Wahl TS, Goss LE, Morris MS, Gullick AA, Richman JS, Kennedy GD, et al. Enhanced recovery after surgery (ERAS) eliminates racial disparities in postoperative length of stay after colorectal surgery. Ann Surg 2017 Jun 7 [Epub]. https://doi.org/10.1097/SLA.0000000000002307.

5. Miller TE, Thacker JK, White WD, Mantyh C, Migaly J, Jin J, et al. Reduced length of hospital stay in colorectal surgery after implementation of an enhanced recovery protocol. Anesth Analg 2014; 118:1052-61.

6. ERAS Compliance Group. The impact of enhanced recovery protocol compliance on elective colorectal cancer resection: results from an international registry. Ann Surg 2015;261:1153-9.

7. Thiele RH, Rea KM, Turrentine FE, Friel CM, Hassinger TE, McMurry TL, et al. Standardization of care: impact of an enhanced recovery protocol on length of stay, complications, and direct costs after colorectal surgery. J Am Coll Surg 2015;220:430-43.

8. Shetiwy M, Fady T, Shahatto F, Setit A. Standardizing the protocols for enhanced recovery from colorectal cancer surgery: are we a step closer to ideal recovery? Ann coloproctol 2017;33:86-92. 